\title{
CARACTERÍSTICAS DO ADULTO, GENITÁLIA E FORMAS IMATURAS DE GONIPTERUS GIBBERUS BOISDUVAL E G. SCUTELLATUS GYLLENHAL (COLEOPTERA, CURCULIONIDAE) ${ }^{1}$
}

\author{
Germano H. Rosado-Neto ${ }^{2}$ \\ Marinêz Isaac Marques ${ }^{3}$
}

\begin{abstract}
CHARACTERISTICS OF ADULT, GENITALIA AND IMMATURE FORMS OF Gonipterus gibBerus Boisduval and G. SCUTEllatus Gyllenhal (Coleoptera, CurculionidaE). Adults and immature forms of $G$. gibberus Boisduval, 1835 and $G$. scutellatus Gyllenhal, 1833 are redescribed briefly. A morphologic study of male and female genitalia with illustrations and keys for the identification of these species are included. The records on the female genitalia are presented for the first time.

KEY WORDS. Coleoptera, Curculionidae, Gonipterus, genitalia, immature forms
\end{abstract}

Poucos são os trabalhos referentes a Gonipterus gibberus Boisduval, 1835 e Gonipterus scutellatus Gyllenhal, 1833 onde são apresentados caracteres que auxiliem no processo de identificação destas espécies.

Ultimamente, o Centro de Identificação de Insetos Fitófagos do Departamento de Zoologia da Universidade Federal do Paraná tem recebido exemplares destas espécies, demonstrando com isto a dificuldade encontrada por profissionais de diversas áreas no momento da identificação das mesmas.

Observa-se que a bibliografia referente (MARELLI 1926a,b,c; LEA 1927), além das descrições originais, não permite identificar com segurança os adultos daquelas espécies, mesmo porque as diferenças existentes não são facilmente perceptíveis.

Ao contrário dos adultos, as formas imaturas (larva e pupa) apresentam caracteres morfológicos externos facilmente distintos, contribuindo para a identificação correta do material (ROSADO-NETO \& FREITAS 1982; SANCHES 1993).

VIDAL (1955) apresentou um longo histórico sobre as discussões e controvérsias entre os autores da época quanto à nomenclatura e correta identificação das espécies mencionadas. No mesmo trabalho apresentou um estudo morfológico sobre a genitália dos machos de G. gibberus e G. scutellatus, nada referindo sobre a genitália da fềmea.

FREITAS (1991a,b) discutiu os aspectos biológicos dos adultos e formas imaturas de G. gibberus, fazendo referência à alimentação e ciclo biológico.

1) Contribuição número 911 do Departamento de Zoologia, Universidade Federal do Paraná.

2) Departamento de Zoologia, Universidade Federal do Paraná. Caixa Postal 19020,

81531-990 Curitiba, Paraná, Brasil. Pesquisador do CNPq.

3) Departamento de Biologia, Instituto de Biociências, Universidade Federal de Mato Grosso. Avenida Fernando Corrêa da Costa, 78090-390 Cuiabá, Mato Grosso, Brasil. Bolsista da CAPES. 
Rosado-Neto (1993) registrou G. scutellatus para o estado de São Paulo, fez algumas considerações taxonômicas sobre G. gibberus e apresentou uma relação dos trabalhos, principalmente sul-americanos, publicados até aquela oportunidade, envolvendo ambas as espécies.

Visando contribuir para facilitar a identificação de G. gibberus e G. scutellatus, apresenta-se: chave de identificação com caracteres dos adultos e formas imaturas; redescrição sucinta dos mesmos; descrição e ilustrações da genitália masculina e feminina. O estudo sobre a genitália feminina é apresentado pela primeira vez, assim como a elaboração de uma chave de identificação.

\section{MATERIAL E MÉTODOS}

O material estudado pertence à Coleção de Entomologia Pe. J.S. Moure, Departamento de Zoologia, Universidade Federal do Paraná.

A genitália foi tratada a quente em hidróxido de potássio $(\mathrm{KOH})$ a $10 \%$. As dimensões das formas imaturas são aquelas registradas por ROSADO-NETO \& FREITAS (1982) para G. gibberus e SANCHES (1993) para G. scutellatus. O comprimento do adulto foi medido desde a margem anterior do protórax até o ápice dos élitros, em vista dorsal ao longo da sutura, e expresso em milímetros. A terminologia adotada nas descrições das genitálias masculina e feminina foram basicamente aquelas estabelecidas por SHARP (1918) e TANNER (1927), respectivamente.

\section{Chave de identificação}

1. Larva (Fig. 1) e pupa: abdome sem faixas longitudinais escurecidas. Adulto (Fig. 2): Rostro uniformemente preto exceto, às vezes, no epístoma. Élitros, próximo ao meio, com escamas esbranquiçadas formando, de cada lado, larga faixa oblíquo-transversal (Fig. 2); úmeros raramente com algumas escamas pretas; estas ausentes no protórax e tubérculos basais dos élitros; tubérculos subumerais proeminentes. Região pleural do pro-, meso-, metatórax (Fig. 3) e abdome com escamas estreitas, alongadas, levemente espatuladas. Genitália macho (Figs 4-9); fêmea (Figs 10-13), oitavo esternito com as extremidades látero-basais recurvadas para fora, e espícula ventral com os braços apicais afilados e curvos (Fig. 13) ............... gibberus

- Larva e pupa (Figs 14,15): Abdome com três faixas longitudinais (duas laterais e uma dorso mediana obsoleta) pretas ou verde-escuras, pouco menos evidentes na pupa. Adulto (Fig. 16): Rostro preto nos lados, castanho-avermelhado no meio. Élitros sem escamas esbranquiçadas formando faixa oblíquo-transversal; escamas pretas adensadas látero-dorsalmente no protórax, sobre os úmeros e nos tubérculos basais dos élitros; tubérculos subumerais pouco proeminentes. Região pleural do pro-, meso-, metatórax (Fig. 17) e abdome com escamas alargadas e espatuladas. Genitália macho (Figs 18-21); fêmea (Figs 22-25), oitavo esternito com as extremidades látero-basais e braços apicais da espícula ventral, retilíneos (Fig. 25) ............ scutellatus 

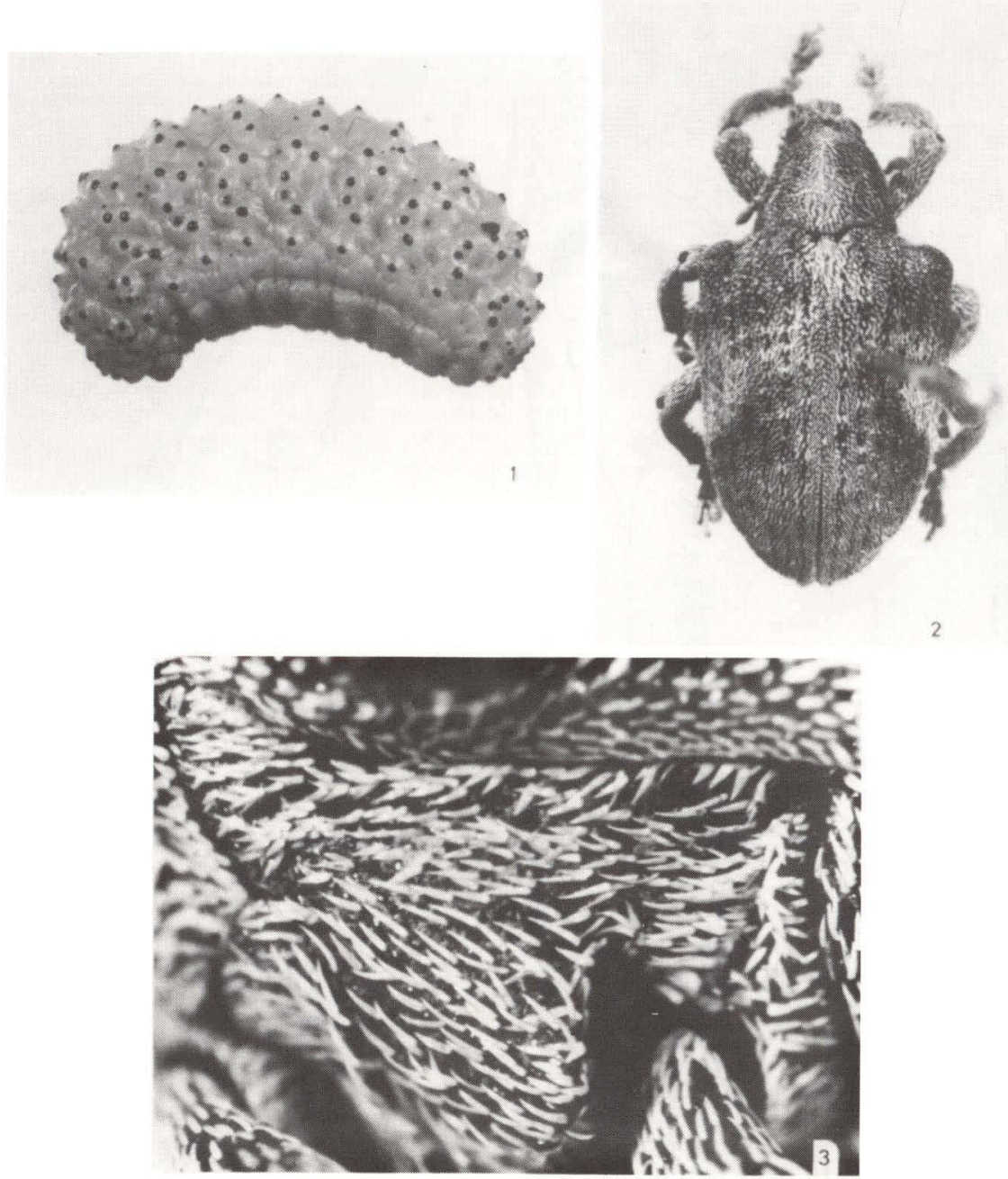

Figs 1-3. Gonipterus gibberus. (1) Larva, vista lateral; (2) adulto, vista dorsal; (3) detalhe das escamas do metasterno e metepisterno, vista lateral.

\section{Gonipterus gibberus Boisduval, 1835}

Figs $1-13$

Gonipterus gibberus Boisduval, 1835: 324 (desc). - Wibmer \& O'Brien, 1986: 110 (cat.). - Rosado-Neto, 1993: 466.

Dacnirotatus bruchi Marelli, 1926a: 630 (desc.). - Marshall, 1927: 215 (sin.).

Formas imaturas. Descritas por RosAdo-NeTO \& FreiTAS (1982). Larva (Fig. 1). Hábito aéreo, ápoda, cabeça retrátil, corpo amarelo-creme, com pequenas manchas pretas, arredondadas; abdome sem faixas longitudinais escurecidas; comprimento: 10,8-13,3 $(\mathrm{n}=15)$. 


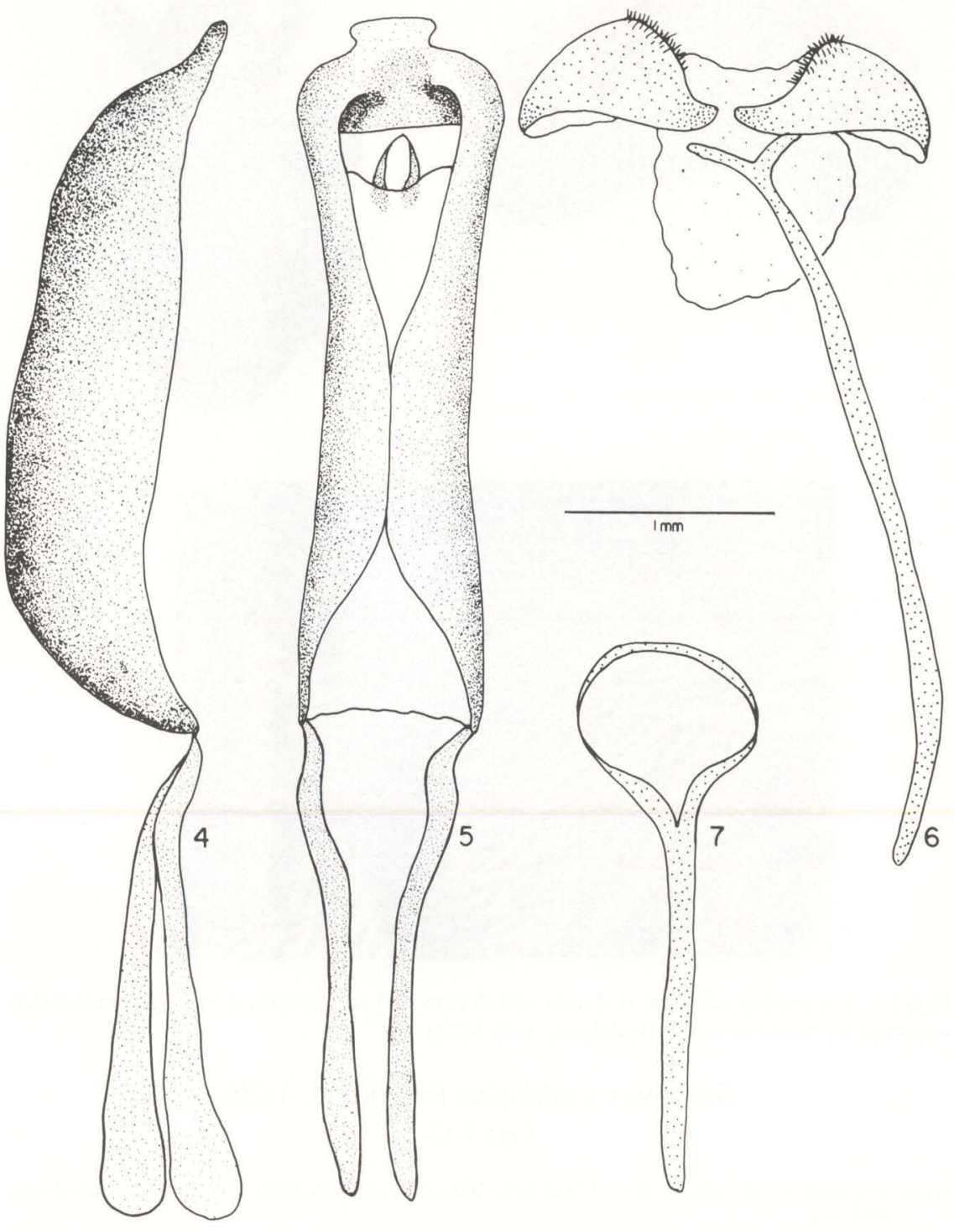

Figs 4-7. Gonipterus gibberus, genitália masculina. (4-5) Lobo médio, vistas lateral e dorsal; (6) oitavo esternito e espicula gastral; (7) tégmen. 

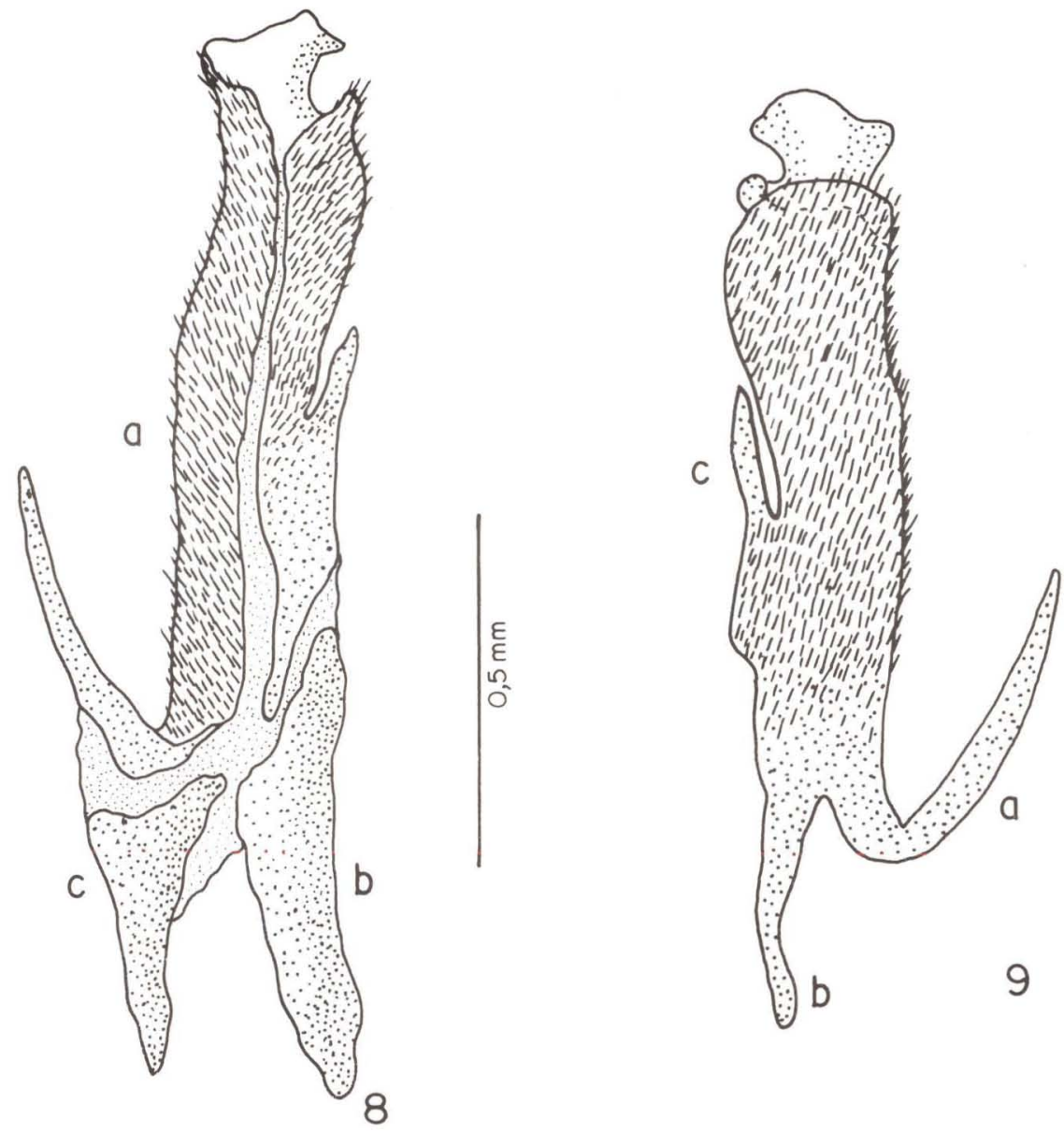

Figs 8-9. Gonipterus gibberus, genitália masculina, armadura do saco interno. (8) Vista ventral, (a) peça anterior, (b,c) peças posteriores; (9) peça anterior, vista dorsal, $(a, b)$ processos basais, (c) processo mediano.

Pupa. Hábito subterrâneo, cor amarelo-creme, últimos segmentos abdominais com tubérculos mais proeminentes e com cerdas castanho-ferrugíneas; os tubérculos escurecidos da larva desaparecem nesta fase; comprimento: 6,6-8,8 $(\mathrm{n}=18)$.

Adulto (Fig. 2). Comprimento médio do macho e fêmea variando, respectivamente, de 7,0-9,2 (n=14) e 8,0-9,2 ( $\mathrm{n}=19)$. Subelíptico, convexo, cerca de duas vezes mais longo que a sua largura umeral.

Tegumento castanho-claro à escuro; preto no rostro e cabeça. Corpo densamente revestido por escamas curtas, estreitas, mais ou menos amareladas. Élitros com faixa mediana, oblíquo-transversal, de escamas pouco mais alongadas e esbranquiçadas; úmeros raramente com algumas escamas pretas; estas ausentes no pronoto e tubérculos basais dos élitros. Região pleural e ventral do pro-, meso-, 


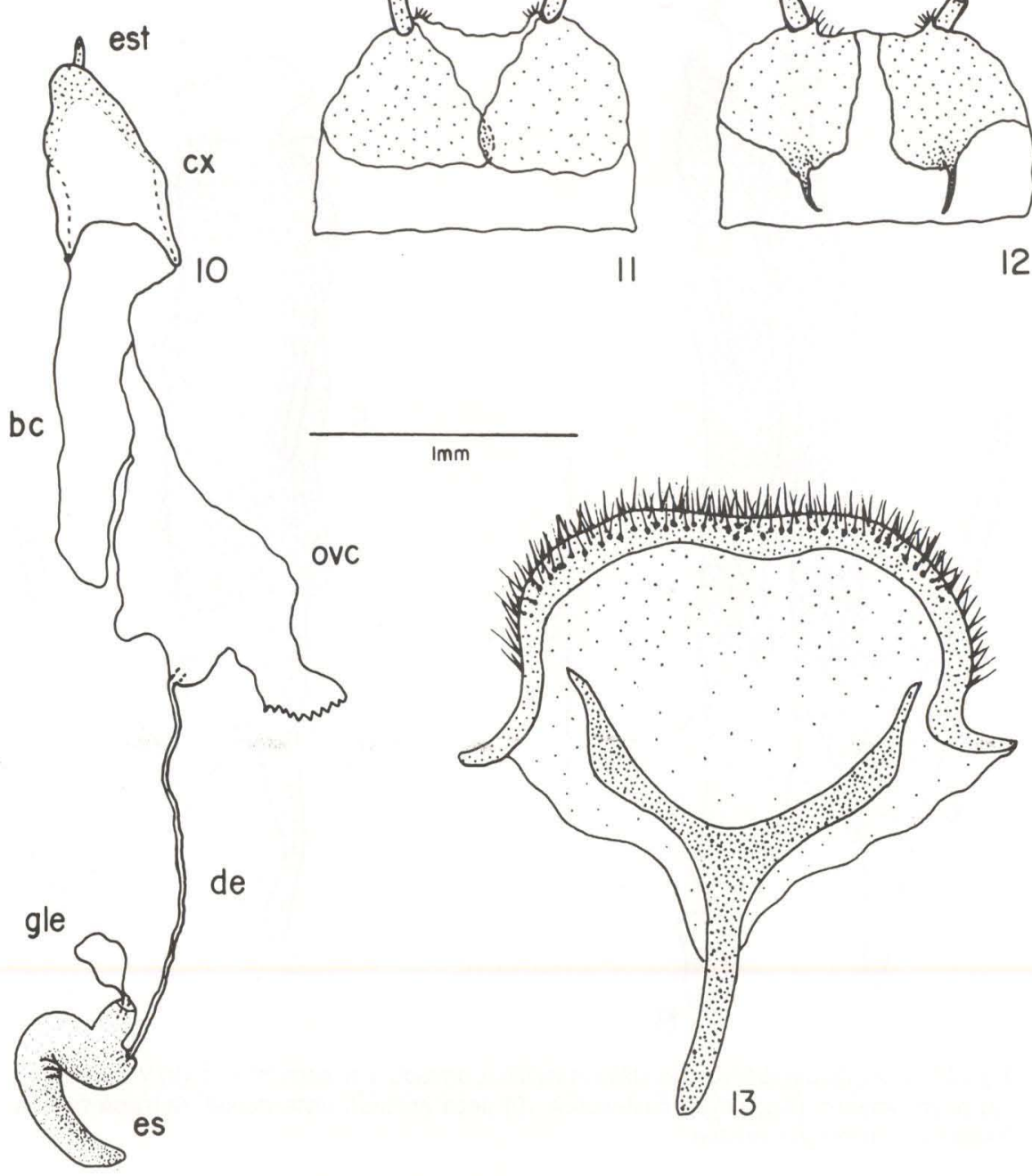

12

Figs 10-13. Gonipterus gibberus, genitália feminina. (10) Genitália em vista lateral; (11-12) coxitos e estilos em vistas dorsal e ventral respectivamente; (13) oitavo esternito. (bc) Bolsa copuladora, (cx) coxito, (de) ducto espermatecal, (es) espermateca, (est) estilo, (gle) glândula espermatecal, (ovc) oviduto comum.

metatórax (Fig. 3) e abdome com escamas estreitas, alongadas, levemente espatuladas. Rostro curto, reto, subcilíndrico, tão longo quanto largo no ápice; interorbital quase tão larga quanto o rostro na base, com uma fovéola profunda. Pronoto transverso, subcônico, pouco estreitado na frente; posteriormente mais largo e com margem bissinuada; com pontuação densa, um tanto profunda, formando granulações. Élitros convexos, uma vez e meia mais longos que sua largura umeral; úmeros salientes e arredondados; dorsalmente, perto da base, com uma forte protuberância 
na terceira interestria e uma menor, às vezes obsoleta, na quinta interestria; tubérculo subumeral, atrás e abaixo dos úmeros, subcônico, forte, com ápice arredondado. Fêmures claviformes, subiguais, com diminutos dentículos na face ventral, mais evidentes nos posteriores. Tíbias subcomprimidas, denteadas na face ventral e mucronadas no ápice.

Abdome. Quinto esterno com margem apical truncada e superfície mediana subplana (macho) ou com margem apical arredondada, levemente acuminada ao meio e com forte depressão mediana (fêmea).

Genitália masculina. Oitavo esternito (Fig. 6): dividido em duas placas esclerotinizadas, subtriangulares, unidas por área membranosa; margem apical arredondada, sinuosa no lado interno, pilosidade curta e esparsa. Espícula gastral (Fig. 6) cilíndrica, fina, muito alongada, cerca de seis a sete vezes mais longa que o oitavo esternito, levemente curva no ápice; base bifurcada ligada às placas do esternito através de um tecido membranoso.

Lobo médio (Figs 4, 5) alongado, ligeiramente estreitado na região mediana, ápice levemente assimétrico pouco mais alargado e com uma larga projeção mediana; quase duas vezes mais longo que os apódemas basais; em vista lateral levemente curvo.

Tégmen (Fig. 7) esclerotinizado, com apódema ventral longo. Saco interno revestido por pequenas espículas agudas mais adensadas na face dorsal; armadura do saco interno (Figs 8,9) constituída por três peças esclerotinizadas, distintas, ligadas entre si por membranas; uma anterior (Fig. 8a) alongada e duas posteriores (Fig. 8b,c) menores. Peça anterior (Fig. 8a) densamente revestida por pilosidade curta; oca, de aspecto tubular, aberta em ambas as extremidades; na face ventral com as bordas separadas por estreita faixa membranosa longitudinal; em vista dorsal (Fig. 9) a região posterior, no lado direito, com um processo alongado, curvo, dilatado na base e afilando para o ápice (Fig. 9a), atingindo quase a metade da mesma; no lado esquerdo, com dois processos, um basal (Fig. 9b) estreito, alongado, e outro, na porção mediana (Fig. 9c), curto, acuminado. As peças posteriores (Fig. 8 b,c) pequenas, levemente côncavas, posicionadas na base da peça anterior, uma a cada lado; a da esquerda (Fig. 8c) menor e com aspecto subtriangular e a da direita (Fig. 8b), alongada.

Fêmea. Oitavo esternito (Fig. 13) com largura máxima maior que o comprimento da espícula ventral; margem apical arredondada, pigmentada, pilosidade curta adensada, com as extremidades látero-basais recurvadas para fora. Espícula ventral bifurcada apicalmente, com os braços estreitos, subiguais no comprimento; os braços apicais afilados e curvos formando um ângulo bem aberto entre si.

Coxito (Figs 11-12) transverso, cerca de duas vezes mais largo que longo; fracamente esclerotinizado; margem lateral arredondada, pouco estreitado para o bordo apical, este levemente sinuoso, pouco mais projetado onde se insere o estilo; pilosidade restrita às regiões laterais; em vista ventral (Fig. 12) cada coxito com projeção basal estreita, alongada e acuminada. Estilo cilíndrico pouco alongado, apical. Bolsa copuladora (Fig. 10) curta, inteiramente membranosa. Porção final do oviduto comum dilatado e com textura semelhante ao da bolsa copuladora. Espermateca (Fig. 10) com cápsula fortemente curvada e pigmentada, pouco mais dilatada 
anteriormente e subacuminada no ápice; glândula espermatecal vesicular, menor que a espermateca; ducto espermatecal (Fig. 10) mais longo que a bolsa copuladora e ligado ao oviduto comum, distante da vagina.

Distribuição geográfica na América do Sul. Argentina, Uruguai e Sul do Brasil (Paraná, Santa Catarina e Rio Grande do Sul).

Material examinado. BRAsIL, Paraná: Colombo, uma fêmea 26-XI-1983, Souza leg., um macho 19-VIII-1988, Pietrowski leg.; três machos, quatro fềmeas 13-VI-1991, Sanches leg.; Curitiba, um macho, duas fêmeas XI-1978, uma fềmea 4-XII-1978, dois machos XII-1978, um macho, uma fêmea 13-I-1981, um macho 17-XII-1981, um macho 2-I-1982, um macho 4-I-1982, Rosado-Neto leg; um macho, X-1978, três fêmeas 22-X-1978, S. Freitas leg.. Santa Catarina: Correia Pinto, um macho 21-XI-1983, Iede leg.; Lages, três machos 5-III-1982, R. Fenilli leg.. Argentina, Buenos Aires: Buenos Aires, um macho III-1939, J. Bosq leg.

\section{Gonipterus scutellatus Gyllenhal, 1833}

Figs $14-25$

Gonipterus scutellatus Gyllenhal in Schoenherr, 1833: 458 (desc.). - Wibmer \& O'Brien, 1986: 110 (cat.). - Rosado-Neto, 1993: 466.

Dacnirotatus platensis Marelli, 1926a: 640 (desc.). - Marshall, 1927: 215 (sin. de G. gibberus). Gonipterus platensis; Marshall, 1928: 263 (reval.). - Wibmer \& O'Brien, 1986: 110 (cat., sin.). Goniopterus marellii Uyttenboogaart in Marelli, 1928a: 77 (desc.). - Marelli, 1928b: 29 (sin. de G. platensis).

Formas imaturas. Descritas por SANCHES (1993).

Larva (Fig. 14). Semelhante à de G. gibberus, exceto pela presença, no abdome, de três faixas longitudinais verde-escuras (duas látero-dorsais mais distintas e uma dorso-mediana um tanto obsoleta). Comprimento: 9,2-11,3 ( $\mathrm{n}=19)$.

Pupa (Fig. 15). Semelhante à de G. gibberus, exceto pelo tamanho pouco menor, 7,0-11,3 $(\mathrm{n}=27)$ e pela presença das três faixas longitudinais escurecidas, pouco mais apagadas, que permanecem nessa fase.

Adulto (Fig. 16). Comprimento médio do macho e fềmea variando, respectivamente, de 5,7-8,9 $(n=35)$ e 7,5-9,4 $(n=46)$.

Tegumento castanho-escuro, rostro preto nos lados, castanho-avermelhado no meio; preto na cabeça. Revestimento escamoso, mais notável ventralmente, com três tipos de escamas: 1) na face dorsal estreitas, amarelo-claras ou escuras; 2) escamas pretas ou enegrecidas dorso-lateralmente no protórax e base dos élitros, especialmente sobre os úmeros e tubérculos; às vezes, presentes nos lados do rostro acima dos escrobos, nas tíbias e nos élitros, de forma irregular, esparsas e até mesmo ausentes em uma destas regiões; 3 ) na região pleural do pro-, meso-, metatórax (Fig. 17) e abdome, amarelo-esbranquiçadas, largas, espatuladas e densas. Élitros na base, logo abaixo e atrás dos úmeros, com tubérculo subumeral pouco proeminente. Demais caracteres como em G. gibberus.

Genitália masculina (Figs 18-20). Lobo médio, tégmen e oitavo esternito como em G. gibberus; espícula gastral (Fig. 20) espessa. Saco interno revestido por espículas mais adensadas e achatadas; armadura do saco interno (Fig. 21) constitui- 

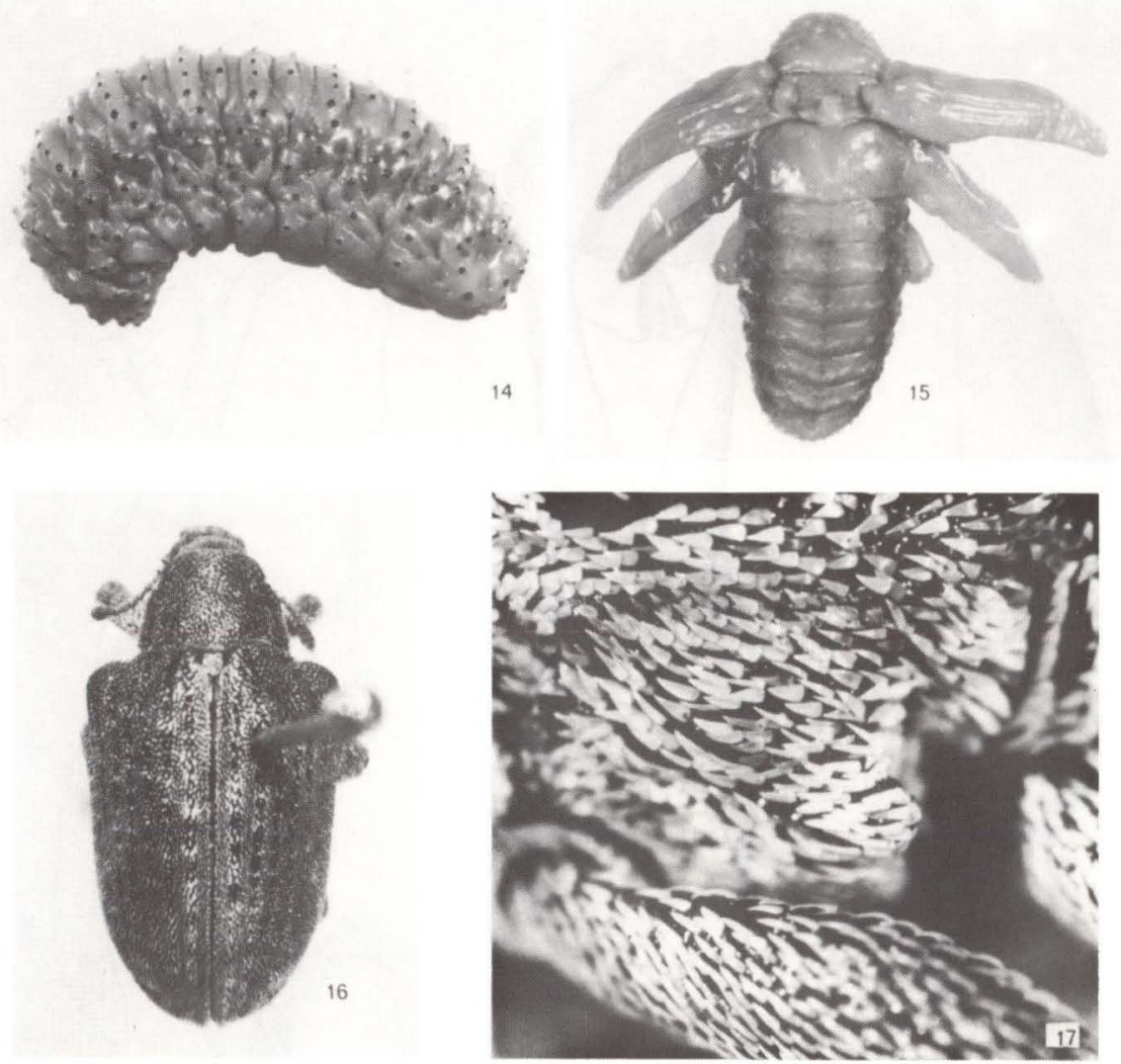

Figs 14-17. Gonipterus scutellatus. (14) Larva, vista lateral; (15) pupa, vista dorsal; (16) adulto, vista dorsal; (17) detalhe das escamas do metasterno e metepisterno, vista lateral.

da por três peças esclerotinizadas distintas e ligadas entre si por membranas: uma anterior (Fig. 21 a) ovalada, deprimida, oca, e duas posteriores (Fig. 21 b,c) estreitas e côncavas. Peça anterior revestida por membrana com pilosidade curta e adensada; na base em vista dorsal, com dois processos laterais (Fig. $21 \mathrm{~d}, \mathrm{e}$ ) estreitos, cilíndricos, acuminados no ápice, levemente curvados, atingindo cerca da metade do comprimento da peça anterior; o da direita (Fig. 21 d), basal e pouco mais longo que o da esquerda, este (Fig. 21e) pouco mais próximo da região mediana. Peças posteriores (Fig. 21b,c) com comprimentos subiguais ao da peça anterior; a da direita (Fig. 21b) levemente côncava pouco mais larga que a da esquerda (Fig. 21 c).

Fêmea. Oitavo esternito (Fig. 25) semelhante ao de G. gibberus, diferindo nas extremidades látero-basais que são retilíneas e nos braços apicais da espícula ventral, retilíneos. 

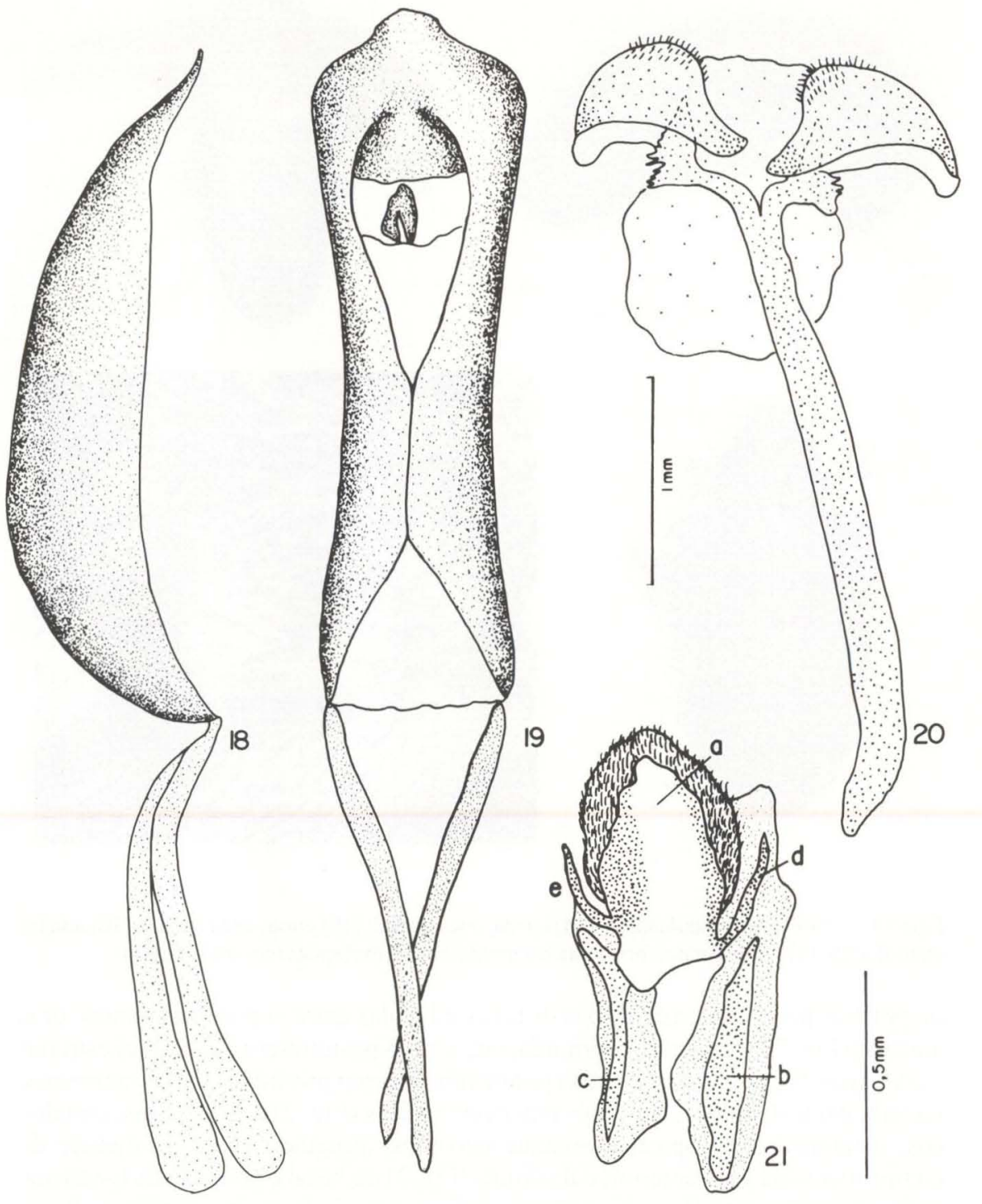

Figs 18-21. Gonipterus scutellatus, genitália masculina. (18-19) Lobo médio, vistas lateral e dorsal; (20) oitavo esternito com espícula gastral; (21) armadura do saco interno, vista dorsal, (a) peça anterior, $(b, c)$ peças posteriores, $(d, e)$ processos laterais. Figuras 18-20 na mesma escala. 


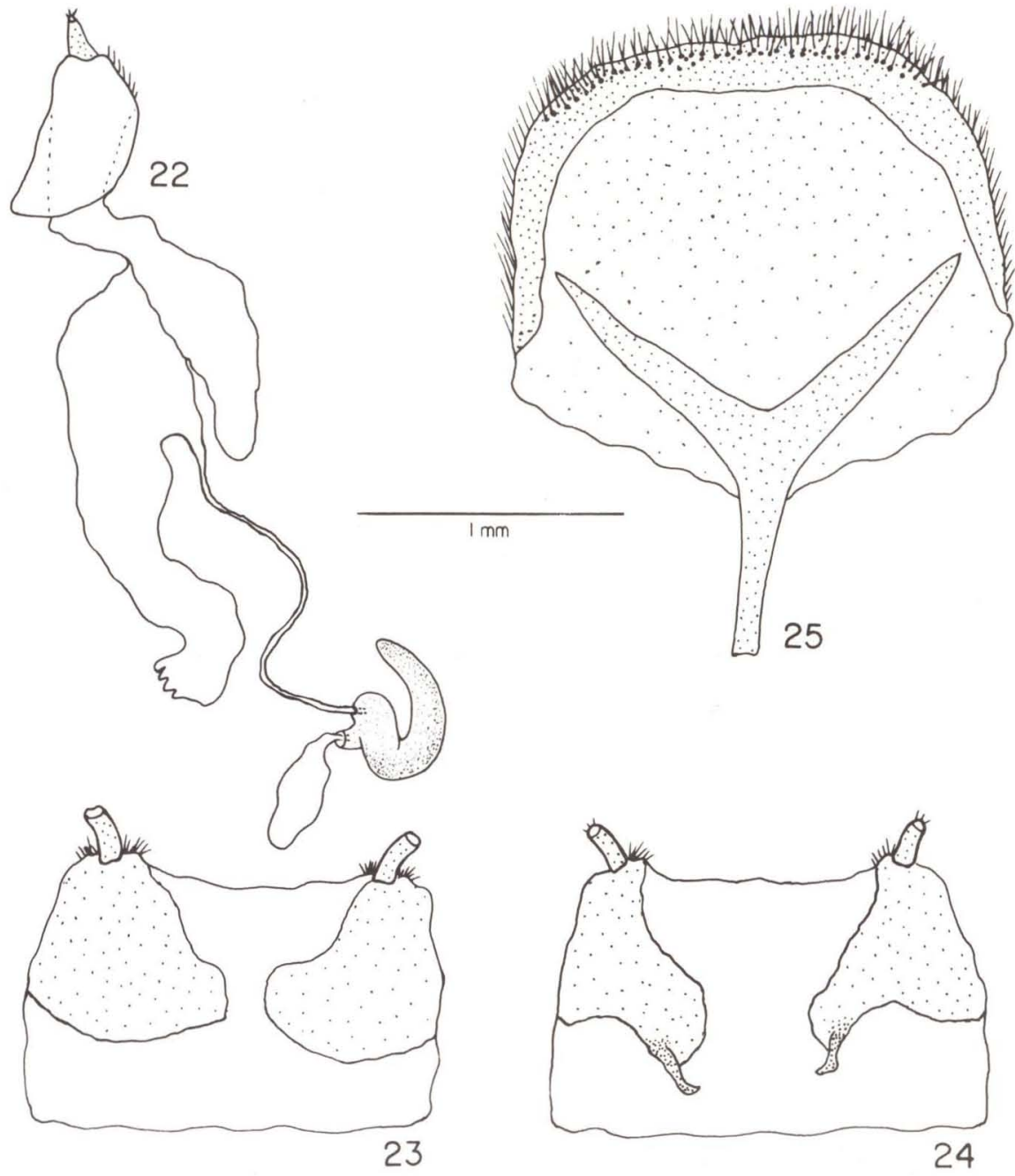

Figs 22-25. Gonipterus scutellatus, genitália feminina. (22) Genitália em vista lateral; (23-24) coxitos e estilos, vistas dorsal e ventral respectivamente; (25) oitavo esternito.

Coxitos e estilos (Figs 23,24) semelhantes ao de G. gibberus, diferindo basicamente, na face ventral (Fig. 24), pela projeção na base de cada coxito mais curta, pouco mais larga, acuminada e curva. Ducto espermatecal (Fig. 22) também ligado ao oviduto comum, mais próximo da vagina.

Distribuição geográfica na América do Sul. Semelhante à de G. gibberus, além de ocorrer no estado de São Paulo, Brasil. 
Material examinado. BRASIL, São Paulo: Itararé (Fazenda Ibiti), um macho, uma fêmea 5.II.1982, Stape leg.. Paraná: Colombo (Embrapa), uma fêmea 19-VIII1988, um macho, quatro fêmeas, 19-VIII-1988, Pietrowski leg., um macho, uma fêmea 13-VI-1991, uma fêmea 12-VII-1991, Sanches leg.; Curitiba, dois machos, duas fêmeas, XI-1978, cinco machos, uma fêmea XII.1978, três machos, três fềmeas 13-I-1981, uma fềmea 17-XII-1981, um macho, três fêmeas 4-I-1982, uma fềmea 13-II-1982, uma fêmea 27-II-1982, dois machos, três fêmeas 16-XII-1986, dois machos 31-XI-1990, quatro macho, três fêmeas 6-XII-1990, uma fêmea 7-XII1990, um macho 10-XII-1990, um macho, duas fêmeas 16-XII-1990, duas fềmeas 21-XII-1990, sete machos XI-1994, quatro fêmeas XII-1994, Rosado-Neto leg.; Três Barras, três machos, três fêmeas 3-III-1989, Brito leg.; Santa Catarina: Lages, três fêmeas 5-III-1982, Fenilli leg.; Correia Pinto, duas fêmeas 21-XI-1983, Iede leg.. Argentina, La Plata: XI-1944, um macho, Martinez leg.; Buenos Aires: Tandil, um macho, uma fêmea XII-1964.

\section{DISCUSSÃO}

As larvas e pupas se distinguem basicamente pela presença (G. scutellatus) ou ausência ( $G$. gibberus) das três faixas longitudinais escurecidas no abdome.

Os adultos são muito semelhantes quanto à morfologia externa, diferindo basicamente pelos caracteres apresentados na chave, especialmente pela coloração do tegumento, tipos de escamas e tubérculo subumeral.

As principais diferenças observadas na genitália masculina são referentes à: 1) espícula gastral mais fina em G. gibberus e mais espessa em G. scutellatus; e 2)aos escleritos que compõem a armadura do saco interno do lobo médio, que estão de acordo com VIDAL (1955), exceto pelos seguintes aspectos: a) em G. gibberus (Fig. 9) a peça anterior apresenta no lado esquerdo dois processos: um basal (Fig. 9b), estreito, alongado e outro na porção mediana (Fig. 9c), curto e acuminado, não mencionado em VIDAL (1955); b)em G. scutellatus, a armadura do saco interno do lobo médio difere pela forma da peça anterior, comprimento e posição do braço esquerdo da mesma. O lobo médio, tergito VIII e esternito VIII são semelhantes nas duas espécies.

A genitália feminina, estudada e ilustrada pela primeira vez, também apresenta algumas diferenças significativas. Em G. gibberus, o esternito VIII com as margens látero-basais recurvadas para fora; espícula ventral do esternito VIII com os braços apicais mais abertos e sinuosos; coxito, ventralmente na base, com um prolongamento estreito e reto. Em G. scutellatus o esternito VIII com as margens látero-basais não recurvadas para fora; espícula ventral do esternito VIII com os braços apicais retos; coxito, ventralmente na base, com prolongamento curto, mais espesso e levemente curvo. Demais estruturas semelhantes em ambas as espécies.

AGRADECIMENTOS. À D.S. Napp pela leitura e sugestões ao manuscrito, a A.M. Sakakibara pelas fotografias e à Direção do Colégio Nossa Senhora Medianeira pela permissão de coleta nas dependências do mesmo. 


\section{REFERÊNCIAS BIBLIOGRÁFICAS}

Boisduval, J.B.A. 1835. Voyage de découvertes de l'Astrolabe. Exécuté par ordre du Roi, pendant les années 1826-1827-1828-1829, sous le commandement de M.J. Dumont d'Urville. Faune entomologique de l'Ocean Pacifique, avec l'illustration des insectes nouveaux recueillis le voyage, deuxième partie, Coléoptères et autres ordres. Paris, Tastu, 716p.

FreITAS, S. 1991a. Observações sobre a alimentação de Gonipterus gibberus (Boisduval, 1835) (Coleoptera, Curculionidae) em eucaliptos. An. Soc. ent. Bras. 20 (2): 333-338.

FreITAS, S. 1991b. Biologia de Gonipterus gibberus (Boisduval,1835) (Coleoptera, Curculionidae) uma praga de eucalipto. An. Soc. ent. Bras. 20 (2): 339-344.

LEA, A.M. 1927. Australian Curculionidae of the family Gonipterides. Proc. R. Soc. Vict. 39: 76-112.

MARELLI, C.A. 1926a. La plaga de gorgojos de los eucaliptos, debida a "Dacnirótatus Bruchi" Mar. y experiencias sobre la desinsectatión de los árboles atacados. Mems. Minist. Obr. públ., Buenos Aires, 1924/1925 (1926): 597-646.

1926b. La plaga de gorgojos de los eucaliptos, debida a "Dacnirótatus Bruchi" Mar. y experiencias sobre la desinsectatión de los árboles atacados. Inf. Jard. Zool. La Plata (1926): 34-46.

1926c. La plaga de los gorgojos de los eucaliptos. Revta Soc. ent. Argent.

1 (1): 14-22.

1928a. Estudio sobre una peste de los eucaliptos descubierta en la Argentina. Buenos Aires, Ministerio de Obras Públicas, 138p.

1928b. Las especies invasoras pueden dar origen a nuevas especies. Revta chil. Hist. nat. 32: 27-30.

Marshall, G.A.K. 1927. New injurious Curculionidae (Col.). Bull. ent. Res. 17 (3): 199-218.

1928. New injurious Curculionidae (Col.). Bull. ent. Res. 18 (3): 257-266.

Rosado-Neto, G.H. 1993. Gonipterinae dos Eucaliptos: primeiro registro de Gonipterus scutellatus para o estado de São Paulo, Brasil, e algumas considerações sobre G. gibberus (Coleoptera, Curculionidae). Revta. bras. Ent. 37 (3): 465-467.

Rosado-Neto, G.H. \& S. Freitas. 1982. Description of immature forms of the eucalyptus weevil Gonipterus gibberus Boisduval, 1835 (Coleoptera, Curculionidae). Rev. Brasil. Biol. 42 (3): 467-471.

SANCHES, M.A. 1993. Influência da temperatura no desenvolvimento de Gonipterus scutellatus Gyllenhal, 1833 (Coleoptera, Curculionidae) em Eucalyptus viminalis Labill, aspectos bionômicos e parasitismo na região de Curitiba. Tese de Mestrado, não publicada, Departamento de Zoologia, Universidade Federal do Paraná, Curitiba, XV+65p.

SHARP, D. 1918. Studies in the Rhynchophora. IV. A preliminary note on the male genitalia. Trans. R. ent. Soc. London 1918: 209-222.

SCHOENHERR, C.J. 1833. Genera et species Curculionidum 1 (2): 383-681. Paris, 
Roret.

TANNER, V. 1927. A preliminary study of the genitalia of female Coleoptera. Trans. Amer. Ent. Soc. 53: 5-50.

VIDAL S., J.A. 1955. Contribución a la aclaración definitiva del problema existente entre las especies "Gonipterus gibberus" Boisd. y "G. platensis" Mar. Notas Mus. La Plata (Zoologia) 18 (157): 31-41.

WibMer, G.J. \& C.W. O'Brien. 1986. Annotated checklist of weevils (Curculionidae sensu lato) of South America (Coleoptera: Curculionoidea). Mem. Amer. Ent. Inst. 39: XVI+563p.

Recebido em 30.X.1995; aceito em 02.VII.1996. 